\title{
The Critical Success Factors to Remote Development of Construction Management Skills and Competencies in Nigeria
}

\author{
Uzor Onyia ${ }^{1}$, Charles Egbu², Subashini Suresh³ and Suresh Renukappa³, \\ ${ }^{1}$ Management of Sustainable \& Entrepreneurial Engineering \\ Faculty of Engineering \\ University of Nigeria, Nsukka, Nigeria \\ ${ }^{2}$ Leeds Trinity University \\ Leeds, England, United Kingdom \\ ${ }^{3}$ Faculty of Science and Engineering \\ University of Wolverhampton \\ United Kingdom
}

\section{ABSTRACT}

\section{Purpose}

Construction management skills and competencies (CMSC) are of greatest importance for the industry to succeed and thrive. Some factors are critical to CSMC development. Hence, following the restrictions occasioned by the outbreak of Covid-19 pandemic, this study reviewed and examined these factors to understand their level of influence in the remote development of CMSC adopted by the industry within and post the disruptions induced by the pandemic.

\section{Design/methodology/approach}

This study adopted a quantitative and descriptive research method. Data were sourced from 155 completed and usable survey questionnaires with registered and licensed engineering and construction professionals practicing in both private and public sectors in Nigeria. Participants were drawn from the membership database of the Nigeria Society of Engineers.

\section{Findings}

The identified critical success factors (CSFs) are categorised into organisational factors which include leadership, engineering project networks and eLearning, measurement and review system, strategy and resources, organisational culture, tradition and structure. In addition to individual factors in this order of influence; willingness to learn, promotion and career development, obtaining certified qualification and obtaining respect of peers are CSFs of remote development of CMSC in Nigeria.

\section{Originality/value}

This study is the first to it identifies and examines the CSFs to remote development of construction management skills and competencies (CMSC) tailored to developing countries in Africa. It explores the two categories of CSFs in both remote and traditional CMSC developments and established that the organisational factors remain positively dominants in traditional as well as in remote development of CMSC. It further ranked the individual factors in their order of influence in Nigeria offered insights into motivation of construction management trainees in developing countries and offered areas of improvements like quality of training and certification.

Keywords: Construction Management, Skills Development, Critical Success Factors, Remote Development, Engineering Project Networks.

\subsection{Introduction}


Since the 60's, organised and modern construction in Nigeria has largely been dominated by foreign and imported resources and skills, especially at managerial and technical levels as against using indigenous skills (Nigeria Bureau of Statistic, 2017). Owolabi et al. (2014) identified poor quality of materials and human resources as the main challenges in the industry. The human resources aspect includes knowledge, skills, and competencies of the construction managers. Incompetent construction professionals were a major cause of poor construction quality as alleged by the president of the Building Collapse Prevention Guild (BCPG), Akinola George as published by (Premium Times, 2019). Managing construction project is a complex process with multiple objectives (Saini et al. 2018). To manage these complexities in construction projects, Khattak and Mustafa (2019) endorsed CMSC development to close the shortages and gaps in skills and competencies. Unfortunately, construction management is yet to be institutionalized in Nigerian built environment and hence, it is coordinated along other professional lines in an entrepreneurial style. Although Daniel et al. (2017) noted that entrepreneurs and academics are important players who introduce innovative planning and managerial approaches that will provide the industry with intelligence, knowledge, tools, skills and competencies that are of competitive advantages. Similar to other institutions in built environment, the two conditions to become an engineering professional in Nigeria is registration and continuous professional development as enshrined in COREN Act. (2018). Hence, the focus of regulations toward skills and competencies development in Nigerian built environment necessitated this research.

While remote or distance and cloud computing learning also known as eLearning or digital learning is not new as an alternative to traditional skills and competencies development approach, studies (Almaiah et al. 2020; Micheal, 2020) observed that Covid-19 pandemic has forced the world into speedy embrace of this alternative learning and development approach. And the construction industry was not left out. On the other hand, Saraph et al. (1989) defined critical success factors as those important areas of managerial planning and actions that must be applied to achieve efficiency. In terms of CMSC development they can be viewed as those practices and activities when well implemented, ensure the successful remote development of CMSC. These activities and practices influence every human activity (Neff, 2017). In the context of remote development of CMSC, Naveed et al. (2019) 
defined CSFs as those factors that remain critical for the success of remote development through digital technologies, these factors have impact on teaching and learning of skills and competencies in an immense way and further categorised these CSFs into two groups organisational and individual. This study through a thorough literature review and data from the Nigerian construction industry identified and examined these two groups of CSFs that influences remote development of CMSC. The organisational CSFs are factors introduced by the cultures, structures and traditions of an organisations around the world and they include leadership, collaborations and networking amongst project team members. In contrast, the individual factors are introduced by personal motives of individuals within the organisation and they include willingness to learn, obtaining certified qualification, promotion and career development and respect of peers (Onyia, 2019). Although as illustrated in Figure 1 by Naveed et al. (2019), both organisational CSFs and Individual CSFs share strong digital influence.

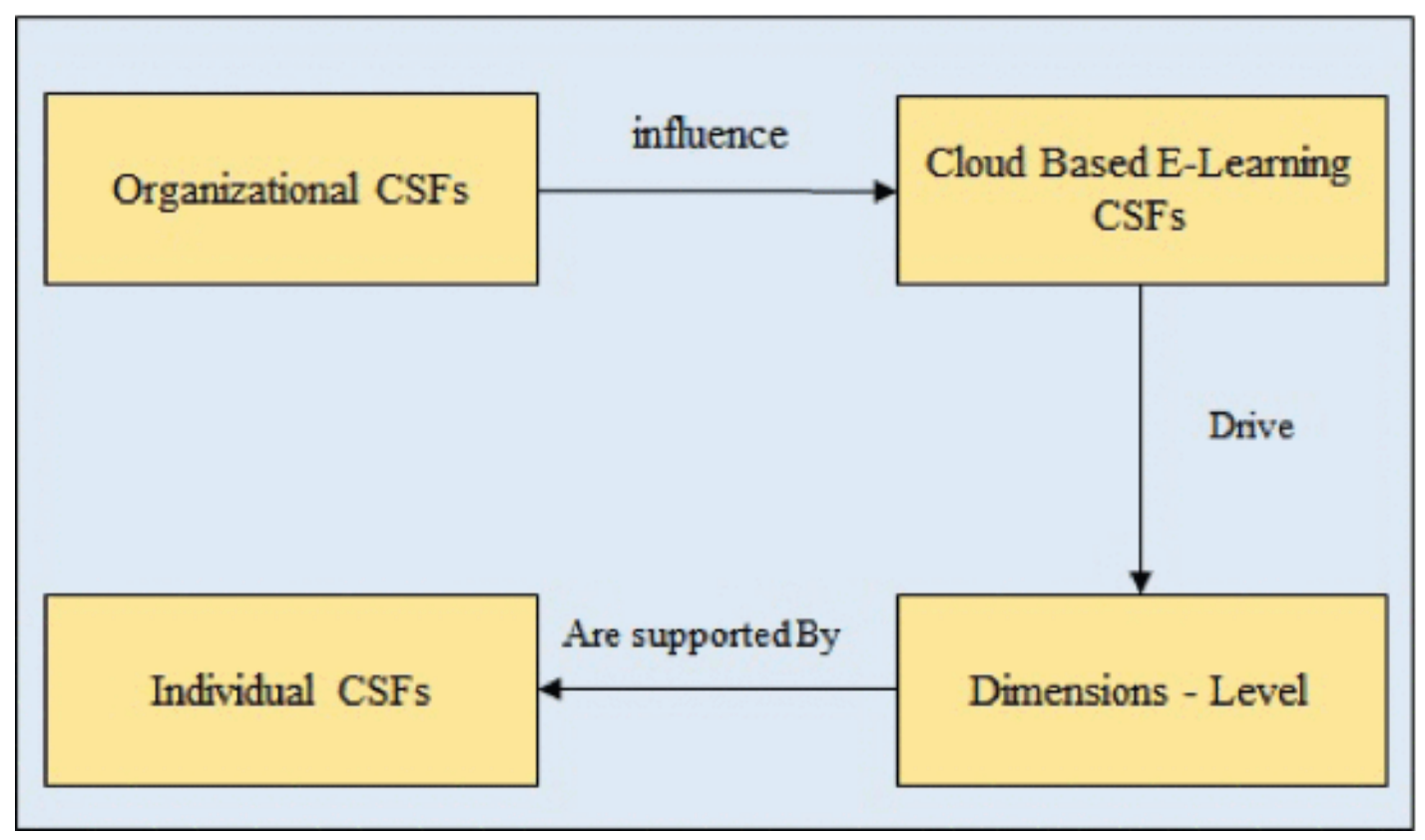

Figure 1: Categorisation of CSFs into Organisational and Individual (Naveed et al. 2019)

Both the organisational and individual CSFs where then tested amongst Nigerian engineers to determine their influence in the remote development of CMSC following the outbreak of Covid-19 pandemic and its global restrictions. 


\subsection{Literature Review}

Leadership defines all organisations; this is why Hickman and Akdere (2018) adjudge that leadership of an organisation plays an important role in influencing the success of skills development. Arif et al. (2017) emphasize that leaders should demonstrate strong willingness to offer and share their knowledge freely with others, to continuously search and learn new knowledge, skills and ideas which would improve their overall competencies. Consequently, they deepen their influence on others to imitate them and increase the inclination of employees' participation (Bolden, 2016). Leadership conveying the importance of CMSC development and improvement to organisation is critical (Mittal and Dhar, 2015). In so doing, they maintain morale and create a culture that promotes skills development and knowledge sharing (Egbu, 2004). As is the case with all changes, the support and commitment of top management is critical to the success of every initiative (Banihashemi et al. 2016).

While leadership is critical to remote development of CMSC, it ushers a clear and well thought out strategy for CMSC development (Kane et al. 2015). Ebrahimi-Mehrabani and Azmi-Mohamad (2015) suggest that the strategy of CMSC development should be linked or integrated with the strategy of the business enterprise as there is always a vision behind the development of every project and organisation. In support of the notion of strategy, the development of a vision for pursuing remote development of CMSC should be compelling and shared. Naveed et al. (2019) referred to this as management support under institution's organisational readiness. It is essential that this vision is understood and supported by all involved for it to work successfully. Hence clear purposes, objectives and goals should be set. To drive home the importance and value of skills, knowledge and competences development, CMSC development strategy should be clearly spelled and embedded into the organisational culture (Ebrahimi-Mehrabani and Azmi-Mohamad, 2015).

Post Covid-19 pandemic, Engineering Project Networks (EPNs) which enables virtual teams work and learning in a globalised manner with disparate and transient individuals bringing together skills and competencies across the world is becoming an inevitable strategy in construction industry (Hosseini et al. 2020). This justifies Zainon et al. (2020) recognition 
of information and communication technology training as one of the current top-ranking CSFs for construction management professionals. EPNs are sustainable working systems which facilitates knowledge sharing and was referred by Onyia et al. (2021) as eLearning and mentoring. EPNs are now the trendy approach for remote development of CMSC and was inevitably increased by the outbreak of Covid-19 pandemic and the restrictions that ensued. Its capability has over time evolved from being purely a static archive of information to being an enormous connector of humans to information and of human to human (Kuo et al. 2013). It has enabled rapid search, access, discovery and retrieval of information, it also supports internal and external communication and collaboration between organisations (Cohen, 2017). EPNs and eLearning as modern learning and sustainable working systems are easily reviewable and measurable.

As emphasized by Phillips and Phillips (2016), initiatives like skills, knowledge and competencies development will suffer the risk of becoming just another management hype, if left unmeasured. Measurement enables tracking of progress made, and helps to determine its advantages and effectiveness (Alizadehsalehi and Yitmen, 2016). Basically, measurement and review provide the basis for evaluation, comparison, control and improvement on the performance of skills, knowledge and competences development (Wong, 2005). Furthermore, review and measurement are also needed to demonstrate the worthiness and value of skills and competencies development initiative to top management and stakeholders (Cohen, 2017). As revealed by Azeiteiro et al. (2015), without such justification, confidence and support of top management to sustain the development will diminish. Measurements and reviews are even more critical for remote development of CMSC as organisation management will need to justify their time and financial investments.

Two years ago, a study by Onyia (2019) revealed that CMSC development is expensive and he reported the unavailability of financial resources. This is also critical as the successfully remote development of CMSC is also dependent on organisational resources. And finance is inevitable for an investment in a technological and any other developmental programme to be made (Ji and Zhang, 2019). Time as a resource is also very important and should receive serious consideration. Organisations should plan to free up time for their workers 
who are recognised participants in remote development of CMSC activities like training sessions, study leave and knowledge sharing. Also, Ellinger and Ellinger (2014) recounted that creating opportunities and time for workers to improve on their skills, knowledge and competencies is critical to guarantee good performance. Therefore, proper planning and budgeting of resources is crucial (Kerzner and Kerzner, 2017). Arguably, one of the key challenges of the industry in achieving effective remote development of CMSC is resources management. Which implies understanding how these resources can better be acquired, allocated and managed for the success of the programme (Noe et al. 2017). Consequently, any investment decisions in remote development of CMSC must be based on a comprehensive consideration of available resources, and not on just the belief that it is "a nice programme to have".

Another critical factor for the successful CMSC development as well as knowledge management is organisational culture (Yann et al. 2017; Egbu, 2004). Fellows and Liu (2015) disclosed that people construct meaning from a process that enables them understand their situation by making sense of the signals they receive. They further explained that this is about connecting signals of their work environment. These signals constitute the values and norms in the organisation known as culture (Fellows and Liu, 2015). Mao et al. (2017) explained that organisational members bring their individual behaviours; these behaviours tend to gradually align and become homogeneous when exposed to the vision and objectives of the organisation to form a culture with the aim of accelerating organisational goals. It is this culture that Hofstede (1984) defined as "a collective programming of the mind which distinguishes the members of one organisation from another" which implies a system of collectively held values and norms that forms a tradition. In the same vein, Hibbert and Huxham (2010) stated that tradition is the preservation or the process of preservation of any symbolic content and practice within an organisation, which involves the development and application of a guiding and constraining authority against possible change of this process of preservation. Generally, a culture supportive of competence is one that highly values and encourages skills and knowledge development, transfer and application (Yann et al. 2017). 
A collaborative culture is a vital condition for knowledge or skills transfer to happen between different individuals and groups (Yang et al. 2018). This is because knowledge and skills transfer require different individuals to come together, interact, network, exchange ideas and share knowledge and skills with each another (Cincera et al. 2018). This is at the core of what engineering project networks (EPNs) is all about (Hosseini et al. 2020). Not just that, collaboration has empirically been proven to be the main contributor to knowledge and skills development (Arif et al. 2015). A fundamental requirement to developing culture is trust (Lleó, et al. 2018). Lack of well-developed mutual trust will make people sceptical of the behaviours and intentions of others, thus, causing them to withhold their knowledge. Improving relationship of trust between different individuals and groups will help facilitate more proactive knowledge sharing and skills development process (Arif et al. 2017). Which is critical in embedding the culture of EPN and remote development of CMSC. Because of how influential culture as a success factor is to skills and knowledge development, studies (Lleó, et al. 2018; Ebrahimi-Mehrabani and AzmiMohamad, 2015; Egbu, 2004) have insisted that organisations should ensure that their skills and knowledge development approaches fit and is embedded into their organisational culture. To this end, is the importance of matching skills and knowledge development approaches with the culture, strategy and core value of an organisation (Oyemomi et al. 2019).

There is a link between appropriate organisational structure, culture and performance (Too and Weaver, 2014). Organisational structure as posit by Maduenyi et al. (2015), has no meaning without a well-conceived organisational culture and an appropriate system. They were of the view that the type of structure adopted by an organisation is determined by the type of the organisation, its goals and objectives. Giving more details, they explained that the type of organisational structure is defined by the hierarchy, roles, responsibilities, accountability, distribution of authority and pattern of communication. Simply put, organisational structure is the established pattern of relationship among components of the organisation. Organisations are structured to attain and support the development of cultural values and norms, which enables them attain their goals and objectives (Maduenyi et al. 2015). This research seeks to understand how these key areas impact the remote development of CMSC in Nigeria. Although Zbirenko and Andersson (2014) had given 
insight that organisational structure is about leadership and communication, and that leadership affects the entire workforce and how they strive to achieve their goals. Additionally, they noted that development issues, personal issues, structure, communication, leadership, and organisational performance, all have effects on each other. Hence, organisational structure affects remote development of CMSC. This study adopted a research method to test these assertions in a developing African country.

\subsection{Methodology}

Following a thorough review of existing CSFs in CMSC across so many countries in section 2. In the context of this study, all identified CSFs that influences remote development of CMSC were categorised into two groups which are organisational factors which are factors triggered by the organisational influences and individual factors which are triggered by personal motives of individuals within the organisations. All the variables that constitute the organisational and individual CSFs were study by Onyia (2019) however, this study aims to review them and identify the CSFs in the remote development of CMSC. This study therefore adopted a quantitative and descriptive research method to count the frequency of opinions of engineers in construction industry as described by Rowley (2014).

Consequently, data was sourced from 155 completed and usable survey questionnaires with registered and licensed civil engineering professionals practicing in both private and public construction sectors in Nigeria. 500 survey questionnaires were initially distributed to randomly selected respondents. This research employed Nigerian Society of Engineers' (NSE) homogenous database for the collection of data because NSE has one of the most updated databases in Nigerian built environment. Secondly, everyone on NSE database has minimum of five years' working experience before being registered which is relevant to the context of this study. Table 1-5 outline the demography of the participants.

\subsection{Results and Discussions}


Specialist research data analysis software, such as Statistical Package for the Social Sciences - SPSS was used to collate and analyse the survey data. Rowley (2014) agrees that this specialist software data analysing tool is well suited for basic statistical reporting in profiling and descriptive research such as this.

4.1 Demography of Respondents

Tables 1-5 present the background knowledge of the questionnaire respondents.

\section{Please insert Table 1 here}

Table 1 presents the stratification of the questionnaire respondents and their levels of management in the.

\section{Please insert Table 2 here}

Table 2 presents the specialisation of respondent's organisation and $82.6 \%$ are construction specialist organisations which helps to validates their views on remote development of CMSC.

\section{Please insert Table 3 here}

Table 3 presents range of respondent's current job position

\section{Please insert Table 4 here}

Table 4 presents the respondent's experience in number of years of practicing construction management in Nigeria.

\section{Please insert Table 5 here}

Table 5 presents the gender and it can be seen that only 1 of the 153 respondents that answered this question is female and this is less than $1 \%$ and shows the degree of gender imbalance in Nigerian engineering sector.

\subsection{Organisational Culture as a CSFs of Remote Development of CSMC}

From the result of the survey in see table 6, respondents were asked to rate culture as a factor that encourage or discourage development of CMSC in Nigeria, from (1) being strongly encourages to (4) strongly discourages. $60.3 \%$ of respondents said culture strongly encourages CMSC development, $17.5 \%$ believe that it encourages which brings the total to $77.8 \%$. On the other hand, $13.5 \%$ opined that culture discourages, while $8.7 \%$ said it 
strongly discourages CMSC development, bringing the total to $22.2 \%$. This indicates that $77.8 \%$ majority of the Nigerian construction professionals surveyed, see culture as an influencing factor that inspires remote development of CMSC.

\section{Please insert Table 6 here}

\subsection{Organisational Tradition as a CSFs of Remote Development of CSMC}

From Table 7, 60.3\% of the respondents assert that tradition strongly encourages remote development of CMSC and $17.5 \%$ noted that it encourages, which brings the total respondents that believe tradition encourages remote development of CMSC to $77.8 \%$. On the other side, $13.5 \%$ and $17.9 \%$ were recorded as respondents that think it discourages and strongly discourages respectively. This brings the total number of respondents that said it discourages to 22.2\%. It could be observed, as shown in Tables 6 and 7, that practitioners perceive culture and the traditional values and norms of an organisation as the same, as shown by the similarity of the figures in both tables. This supports the existing literatures (Hofstede, 1984; Hibbert and Huxham 2010; Fellow and Liu 2015; Mao et al. 2017) definition of organisational culture and tradition. In summary, this implies that respondents view remote development of CMSC as a strategy to increase organisational performance in their respective organisations. By this, remote development and embedment of CMSC is part of the overall corporate strategy of organisations. Hence, culture of an organisation is naturally developed around performance. This literally infers that culture and tradition encourages remote development of CMSC. This result is important for project and HR managers, trainers, commercial, advocacy, policy organisations and other stakeholders in CMSC development to enable the understanding of the influence of their organisational culture and tradition in their overall CMSC development plans and programmes.

Please insert Table 7 here

\subsection{Organisational Structure as a CSF of Remote Development of CSMC}


In Table 8, respondents were asked to rate organisational structure as a factor that influences remote development of CMSC in the Nigeria with (1) meaning strongly encourage and (4) meaning strongly discourage. 54\% of the respondents asserted that it strongly encourages, while $23 \%$ opined that it encourages, which brings the total number of respondents that think it encourages remote development of CMSC to $77 \%$. About $14.3 \%$ are of the view that it discourages, while $8.7 \%$ see it as strongly discourage. This brings the total number of respondents that feel it discourages to $23 \%$. The response of construction professionals supports literature (Too and Weaver, 2014; Zbirenko and Anderson, 2014; Maduenyi et al. 2015) that organisational structure encourages and promote CMSC development. This result correlates with that of organisational culture and tradition in tables 6 and 7. The inference is for trainers, project and HR managers, commercial, advocacy and policy organisations to recognise their organisational structure as part of the strategy in remote development of CMSC.

From the survey conducted, tables 9, 10, 11, and 12 reveal factors that individually motivate construction managers and supervisors in Nigeria. The tables below listed factors that could either encourage or discourage remote development of CMSC in Nigeria. Respondents were asked to rate their preference, in a likert scale, with 1, as strongly encourage factor and 4, strongly discourage.

Please insert Table 8 here

\subsection{Certified Qualification as a CSFs of Remote Development of CSMC}

From table 9, $71.2 \%$ and $16.4 \%$ of respondents noted that obtaining certified qualification is a factor that strongly encourages and encourages them respectively. Only $1.4 \%$ and $11 \%$ asserted that it strongly discourages or discourages them. A total of $87.6 \%$ of respondents noted this as the third influencing individual factor. This implies that obtaining certified qualification is a CSFs in remote development of CMSC among the Nigerian construction professionals. 


\section{Please insert Table 9 here}

\subsection{Respect of Peers as a CSF of Remote Development of CSMC}

From table $10,43.2 \%$ and $29.5 \%$ of respondents noted that obtaining the respect of others is a factor that strongly encourages or encourages them respectively. While $26 \%$ and $1.4 \%$ of respondents noted obtaining respect of others discourages them or strongly discourages them respectively. A total of $72.7 \%$ of respondents asserted that this as an influencing factor. This implies that obtaining the respect of peers is a critical success factor in remote development of CMSC in Nigeria. This result implies that professionals are keen on how they are perceived by others. Construction professionals want to be well recognised amongst their peer after participation in a remote development of CSMC. It is then important for training providers and organisation to acknowledge and apply this revelation for remote CMSC development in Nigeria. This result supports Ojochide et al. (2018) position that Nigeria is a perceptive society and this culture influences every human endeavour in Nigeria.

\section{Please insert Table 10 here}

\subsection{Promotion and Career Development as a CSF of Remote Development of CSMC}

From table $11,87.7 \%$ and $9.5 \%$ of respondents noted that promotion and career development is a factor that strongly encourages or encourages them respectively to participate in remote development of CMSC. Less than $1 \%$ noted it does not encourage them. A total of $97.2 \%$ of respondents noted this as an influencing factor. This implies that promotion and career development is the second individual CSF in remote development of CMSC in Nigeria. This corroborate Odia and Ogiedu (2013) that professional choices are inspired by career development in Nigeria. It is important for organisations, project and HR managers to recognised this in their remote CMSC development strategy. This result has also implied that Nigerian construction professionals are career driven professionals as $97 \%$ is very significant.

\section{Please insert Table 11 here}




\subsection{Willingness to Learn as a CSFs of Remote Development of CSMC}

From table 12 above, $89.3 \%$ and $9.9 \%$ of respondents noted that willingness to learn new things is a factor that strongly encourages or encourages them to participate in remote development of CMSC in Nigeria while less than $1 \%$ think it does not. A total of $99.2 \%$ of respondents noted this as an influencing factor. This implies that willingness to learn is the number 1 individual critical success factor in remote development of CMSC in Nigeria.

\section{Please insert Table 12 here}

The results from tables 6-12 are fascinating as it implies that the Nigerian construction professionals are lovers of knowledge and learning. This revelation will encourage commercial, advocacy and policy organisations, project and HR managers to invest required resources in remote development of CMSC with the understanding that construction professionals consider this investment as an opportunity for further learning, career development, promotion and respect.

From the results in tables 9, 10, 11 and 12, it can be established that the survey respondents distinguished willingness to learn, promotion and career development, certified qualification and respect of peers in this order, as the individual critical success factors in remote development of CMSC in Nigeria. It is worthy to note that willingness to learn which will produce certified qualification, influences promotion and career development which guarantees respect in Nigeria. These CSFs influences the minds of construction managers in Nigeria and should be taken into serious consideration by employers, professional construction organisations, trainers and academia. This reveals some motives and motivations of Nigerian construction managers for remote development of CMSC for training providers, HR managers and organisational leadership to align incentives and compensations with these CSFs and others discussed in the literature review section.

\subsection{Conclusion}

This study contributes to skills and competencies development in construction management area in several ways. First, it identifies and examines the CSFs to remote 
development of construction management skills and competencies (CMSC) tailored to developing countries in Africa. It explores the two categories of CSFs in both remote and traditional CMSC developments and established that the organisational factors which include leadership, engineering project networks and eLearning, measurement and review system, strategy and resources, organisational culture, tradition and structure remain positively dominants in traditional as well as in remote development of CMSC. It further ranked the individual factors in their order of influence were; willingness to learn, promotion and career development, obtaining certified qualification and obtaining respect of peers in this order are CSFs of remote development of CMSC in Nigeria. Findings reveal insights into motivation of construction management trainees in developing countries and offered areas of improvements like quality of training and certification, along with the affiliation of training providers with reputable institutions to enable the award of valuable credentials to trainees. In practice, the findings of the study require organisations and policymakers to encourage and reward CMSC development participants with career promotions.

However, due to the following limitations, the findings of this study should be adopted with caution. Although this study was conducted in a multicultural society like Nigeria, the application in other developing countries may experience discrepancies due to local socioeconomic and cultural factors. Additionally, the sample size was relatively small and the respondents were mostly based in the federal capital city and were all civil engineers. As such, the conclusions may not reflect the perception of a holistic construction professionals in other disciplines and regions of the country. Furthermore, the exploration of CSFs was merely from the perception of construction managers of tertiary education level, thus might be bias towards middle and senior management level. Hence, secondary and vocational education level construction managers like the foremen who constitute bulk of the frontline managers in some small and medium scale construction projects may reveal more insights. These limitations crave for further investigations using larger samples that covers various disciplines and different sizes. This will incorporate the views of wider stakeholders in construction management and more value to the findings present by this study. 


\section{References}

Ahmed, P.K., Lim, K.K. and Zairi, M. (1999), "Measurement practice for knowledge management", Journal of Workplace Learning: Employee Counselling Today, vol. 11(8), pp. 304-311.

Almaiah, M.A., Al-Khasawneh, A. and Althunibat, A., 2020. Exploring the critical challenges and factors influencing the E-learning system usage during COVID-19 pandemic. Education and Information Technologies, 25, pp.5261-5280.

Anyaeji, O (2016), Missing Link in Nigeria's Development: Insufficient Engineers in the Policy Space, Inaugural Speech as the 3oth President of the Nigerian Society of Engineers (NSE) on 16th Jan, 2016.

Arif, M., Al Zubi, M., Gupta, A. D., Egbu, C., Walton, R. O., \& Islam, R. (2017). Knowledge sharing maturity model for Jordanian construction sector. Engineering, Construction and Architectural Management, vol.24(1), pp.170-188.

Alizadehsalehi, S. and Yitmen, I. (2016), 'The Impact of Field Data Capturing Technologies on Automated Construction Project Progress Monitoring', Procedia Engineering, vol.161, pp. 97-103.

Azeiteiro, U. M., Bacelar-Nicolau, P., Caetano, F. J., and Caeiro, S. (2015), Education for sustainable development through e-learning in higher education: experiences from Portugal. Journal of Cleaner Production, vol.106, pp.308-319.

Barba-Sánchez, V. and Atienza-Sahuquillo, C., 2018. Entrepreneurial intention among engineering students: The role of entrepreneurship education. European Research on Management and Business Economics, 24(1), pp.53-61. 
Banihashemi, S., Hosseini, M. R., Golizadeh, H., and Sankaran, S. (2017), Critical success factors (CSFs) for integration of sustainability into construction project management practices in developing countries. International Journal of Project Management, volo.35(6), pp.1103-1119.

Bolden, R. (2016), Leadership, management and organisational development. In Gower handbook of leadership and management development, Routledge, pp. 143-158

Bontis, N. (2001), “Assessing knowledge assets: a review of the models used to measure intellectual capital”, International Journal of Management Reviews, vol. 3(1), pp. 41-60.

Cincera, J., Biberhofer, P., Binka, B., Boman, J., Mindt, L. and Rieckmann, M. (2018), Designing a sustainability-driven entrepreneurship curriculum as a social learning process: A case study from an international knowledge alliance project. Journal of Cleaner Production, vol.172, pp.4357-4366.

Cohen, E. (2017), Employee training and development. In CSR for HR pp. 153-162

Daniel, A.D., Costa, R.A., Pita, M. and Costa, C., (2017), Tourism Education: What about entrepreneurial skills? Journal of Hospitality and Tourism Management, vol.30, pp.65-72.

Dimuna, K. O. (2017), Architectural Education and Practice in Nigeria.

Ebrahimi Mehrabani, S., and Azmi Mohamad, N. (2015), New approach to leadership skills development (developing a model and measure). Journal of Management Development, vol.34(7), pp.821-853.

Egbu, C (2004), Managing knowledge and intellectual capital for improved organizational innovations in the construction industry: an examination of critical success factors, Engineering, Construction and Architectural Management, vol. 11(5), pp. $301-315$ 
Ellinger, E. A. and Ellinger, D. A. (2014). "Leveraging human resource development expertise to improve supply chain managers' skills and competencies", European Journal of Training and Development, Vol. 38 No. 1/2, pp. 118-135. https://doi.org/10.1108/EJTD-o92013-0093

Fellows, R. and Liu, A (2015), Sense-making in the Cross-cultural context of Projects, International Journal of Project Management vol.34, pp.246-257

Garbharran, H., Govender, J. and Msani, T. (2012), Critical Success Factors Influencing Project Success in the construction industry, Acta Structilia vol.2(19)

Gupta, B., lyer, L.S. and Aronson, J.E. (2000), “Knowledge management: practices and challenges", Industrial Management \& Data Systems, Vol. 100(1), pp. 17-21.

Hasanali, F. (2002), "Critical success factors of knowledge management”,

Hauschild, S., Licht, T. and Stein, W. (2001), "Creating a knowledge culture”, The McKinsey Quarterly, vol. 1, pp. 74-81.

Haythornthwaite, C., 2009. Crowds and communities: Light and heavyweight models of peer production. In 2009 42nd Hawaii international conference on system sciences (pp. 110). IEEE.

Hibbert, P. and Huxham, C. (2010), The past in play: Tradition in the structures of collaboration. Organization Studies, vol.31(5), pp.525-554.

Hickman, L. and Akdere, M., (2018), Effective leadership development in information technology: Building transformational and emergent leaders. Industrial and Commercial Training.

Hofstede, G. H. (1984), Culture's consequences - international differences in work-related values (Abridg ed.). Newbury Park, Calif; London, Sage Publications. 
Hosseini, M.R., Edwards, D.J., Singh, T., Martek, I. and Darko, A., 2020. Engineering project networks: providing "sustainable work systems" for construction knowledge workers. Journal of Engineering, Design and Technology.

Ji, Q. and Zhang, D. (2019), How much does financial development contribute to renewable energy growth and upgrading of energy structure in China? Energy Policy, 128, pp.114-124.

Kane, G. C., Palmer, D., Phillips, A. N., Kiron, D., and Buckley, N. (2015), Strategy, not technology, drives digital transformation. MIT Sloan Management Review and Deloitte University Press, vol.14, pp.1-25

Kerzner, H., and Kerzner, H. R. (2017), Project management: a systems approach to planning, scheduling, and controlling. John Wiley \& Sons.

Kuo, F., Tseng, F., Lin, C. I. C., and Tang, W. (2013), Critical success factors for motivating and sustaining women's ICT learning. Computers \& Education, vol.67,

Lleó, A., Agholor, D., Serrano, N., and Prieto-Sandoval, V. (2018), A Mentoring Programme Based on Competency Development at a Spanish University: An Action Research Study. European Journal of Engineering Education, vol.43(5), pp.706-724

Maduenyi, S., Oke, A., Fadeyi, O. and Ajagbe, M (2015), Impact of Organisational Structure on Organisational Performances. International Conference on African Development Issues, Social and Economic Task for Development Track

Mao, P., Li, S., Ye, K., and Cai, H. (2017), A field theory-based model for identifying the effect of organizational structure on the formation of organizational culture in construction projects. KSCE Journal of Civil Engineering, vol.21(1), pp.45-53.

Mittal, S., and Dhar, R. L. (2015), Transformational leadership and employee creativity: mediating role of creative self-efficacy and moderating role of knowledge sharing. Management Decision, vol.53(5), pp.894-910. 
Naveed, Q.N., Qureshi, M.R.N.M., Shaikh, A., Alsayed, A.O., Sanober, S. and Mohiuddin, K., 2019. Evaluating and ranking cloud-based e-learning critical success factors (CSFs) using combinatorial approach. IEEE Access, 7, pp.157145-157157.

Neff, W. (2017), Work and human behaviour. Routledge.

Nigerian Bureau of Statistics (2018), Key Statistics for Nigerian Gross Domestic Product Report (Expenditure and Income Approach) Arrears of 2018

\section{http://www.nigerianstat.gov.ng/}

Noe, R. A., Hollenbeck, J. R., Gerhart, B., and Wright, P. M. (2017), Human resource management: Gaining a competitive advantage. New York, NY: McGraw-Hill Education.

Odia, J. O., and Ogiedu, K. O. (2013), Factors affecting the study of accounting in Nigerian Universities. Journal of Educational and Social Research, vol.3(3), pp.89.

Ojochide, I. M., Ikharehon, J. A., and Joy, I. (2018), Organizational Culture and Knowledge Management: A Study Of Dangote Cement Manufacturing Firms, Obajana, Kogi State, Nigeria. International Journal of Scientific Research and Management, vol.6(07)

Onyia, U. 2019. Improving the Supervisory and Managerial Skills and Competencies Required in Construction Management in Nigeria. PhD Thesis. LBSU.

Onyia, U., Nwoji, C. U. and Anwara, O. A. 2021. The Knowledge, Skills, and Competencies Development Approach of Nigeria Engineers within the Covid-19 Pandemic and Restrictions. International Research Journal of Engineering and Technology (IRJET). Vol. 08. Iss. 08.

Owolabi, J. D., Amusan, L. M., Oloke, C. O., Olusanya, O., Tunji-Olayeni, P. F., Dele, O., \& Omuh, I. O. (2014), Causes and effect of delay on project construction delivery time. 
International Journal of Education and Research, vol.2(4), pp.197-208. http://eprints.covenantuniversity.edu.ng/6199/\#.WR7B-FXyupo

Oyemomi, O., Liu, S., Neaga, I., Chen, H. and Nakpodia, F., 2019. How cultural impact on knowledge sharing contributes to organizational performance: Using the fsQCA approach. Journal of Business Research, 94, pp.313-319.

Premium Times (2019) How to curb incessant building collapse in Lagos - Experts, March 13, 2019, https://www.premiumtimesng.com/regional/ssouth-west/322202-how-to-curbincessant-building-collapse-in-lagos-experts.html

Phillips, J. J., and Phillips, P. P. (2016), Handbook of training evaluation and measurement methods. Routledge

Robertson, M. and Hammersley, G.O. (2000), "Knowledge management practices within a knowledge-intensive firm: the significance of the people management dimension", Journal of European Industrial Training, vol. 24(2/3), pp. 241-253.

Rowley, J., 2014. Designing and using research questionnaires. Management research review.

Saraph, J. V., Benson, P. G., and Schroeder, R. G. (1989), An instrument for measuring the critical factors of quality management. Decision sciences, vol.20(4), pp.810-829.

Saunders, M., Lewis, P. and Thornhill, A (2007), Research methods for business students, (4th ed.). New York: Prentice Hall.

Stack, S., and Bound, H. E. L. E. N. (2012), Exploring new approaches to professional learning: Deepening pedagogical understanding of Singapore CET trainers through metacognition and practitioner-based research. 
Strøm, H.A., Olsen, T.H. and Foss, L., 2020. Tensions for Cultural Entrepreneurs Managing Continuous Innovation: A Systematic Literature Review. International Journal of Arts Management, 23(1), pp.61-78.

Too, E. G., and Weaver, P. (2014), The management of project management: A conceptual framework for project governance. International Journal of Project Management, vol.32(8), pp.1382-1394.

Townsend et al., (2010), To start or not to start: Outcome and ability expectations in the decision to start a new venture, Journal of Business Venturing, vol.25 (2), pp. 192-202

Trevithick, P. (2011), Social work skills and knowledge: A practice handbook. McGraw-Hill Education (UK).

Wong, Y. (2005), Critical success factors for implementing knowledge management in small and medium enterprises. Industrial Management \& Data Systems, vol.105(3), pp.261279 .

Yang, Z., Nguyen, V.T. and Le, P.B., (2018), Knowledge sharing serves as a mediator between collaborative culture and innovation capability: an empirical research. Journal of Business \& Industrial Marketing.

Yann M. Y., Cheng Ling T., and Ramayah, T. (2017), Connect the Silos: Knowledge Management, Absorptive Capacity, Leadership Styles, Organisational Cultures. Proceedings of the International Conference on Intellectual Capital, Knowledge Management \& Organizational Learning, pp.310-315. Retrieved from

Zainon, N., Skitmore, M. and Mohd-Rahim, F.A., 2020. Critical success factors in implementing flexible IT infrastructure in the Malaysian construction industry. International Journal of Construction Management, pp.1-12. 
Zbirenko, A., and Andersson, J. (2014), Effect of organizational structure, leadership and communication on efficiency and productivity: A qualitative study of a public health-care organization

\begin{tabular}{|c|c|c|c|c|c|}
\hline \multirow{4}{*}{ VALID } & & & Frequency & Percent (\%) & Cumulative \% \\
\hline & \multicolumn{2}{|l|}{ Yes } & 128 & 82.6 & 82.6 \\
\hline & \multicolumn{2}{|l|}{ No } & 27 & 17.4 & 100.0 \\
\hline & \multicolumn{2}{|l|}{ Total } & 155 & 100.0 & \\
\hline \multicolumn{2}{|c|}{ QUESTIONAIRE } & PERCENT & \multicolumn{3}{|c|}{ LEVEL OF MANAGEMENT } \\
\hline \multicolumn{2}{|l|}{75} & $48.4 \%$ & \multicolumn{3}{|c|}{ Site Managers- Supervisors - Line Manager } \\
\hline \multicolumn{2}{|l|}{50} & $32.3 \%$ & \multicolumn{3}{|c|}{ Project Managers - Middle Managers } \\
\hline \multicolumn{2}{|l|}{30} & $19 \cdot 3 \%$ & \multicolumn{3}{|c|}{ Project Executives - Senior Manager } \\
\hline
\end{tabular}

Table 1: Stratification of database

Table 2: Specialisation of respondents' organisation

\begin{tabular}{|c|c|c|c|c|}
\hline \multicolumn{5}{|r|}{ Cumulative Percent } \\
\hline \multirow{6}{*}{ VALID } & Project Executive/Directo & 9 & 5.8 & 5.8 \\
\hline & Project Manager/Enginee & 55 & 35.5 & 41.3 \\
\hline & Site Manager/Engineer & 26 & 16.8 & 58.1 \\
\hline & Supervisor/Foreman & 40 & 25.8 & 83.9 \\
\hline & Others & 25 & 16.1 & 100.0 \\
\hline & TOTAL & 155 & 100.0 & \\
\hline
\end{tabular}

Table 3: Range of respondents' current job position

How long have you been involved in managing construction project?
\begin{tabular}{|c|l|l|l|}
\hline & Frequency & Percent (\%) & Cumulative \\
\hline Less than 5 years & 7 & 4.6 & 4.6 \\
\hline
\end{tabular}




\begin{tabular}{|c|c|c|c|c|}
\hline \multirow{6}{*}{ VALID } & 5-6 years & 67 & 44.4 & 49.0 \\
\hline & 6-11 years & 49 & 32.5 & 81.5 \\
\hline & $11-15$ years & 9 & 6.0 & 87.4 \\
\hline & $15-20$ years & 8 & $5 \cdot 3$ & 92.7 \\
\hline & More than 20 years & 11 & 7.3 & 100.0 \\
\hline & Total & 151 & 100.0 & \\
\hline \multicolumn{2}{|c|}{ MISSING } & 4 & & \\
\hline & TOTAL & 155 & & \\
\hline
\end{tabular}

Table 4: Experiences of respondents in construction management in the $\mathrm{NCl}$

\begin{tabular}{|c|c|c|c|c|}
\hline & . & Frequency & Percent (\%) & Cumulative Percent \\
\hline \multirow{3}{*}{ VALID } & Male & 152 & $99 \cdot 3$ & $99 \cdot 3$ \\
\hline & Female & 1 & .7 & 100.0 \\
\hline & Total & 153 & 100.0 & \\
\hline \multirow[t]{2}{*}{ MISSING } & & 2 & & \\
\hline & TOTAL & 155 & & \\
\hline
\end{tabular}

Table 5: Gender of respondents

Rate culture as a factor that encourage or discourage remote development of CMSC

\begin{tabular}{|l|l|l|l|l|}
\hline \multirow{3}{*}{ VALID } & Frequency & Percent (\%) & Cumulative Percent \\
\cline { 2 - 5 } & strongly encourage & 76 & 60.3 & 60.3 \\
\cline { 2 - 5 } & encourage & 22 & 17.5 & 77.8 \\
\cline { 2 - 5 } & discourage & 17 & 13.5 & 91.3 \\
\hline & strongly discourage & 11 & 8.7 & 100.0 \\
\hline & Total & 126 & 100.0 & \\
\hline MISSING & 29 & & \\
\hline TOTAL & 155 & & \\
\hline
\end{tabular}

Table 6: Culture as a factor Influencing in remote development of CMSC in Nigeria

\begin{tabular}{|c|c|c|c|c|}
\hline & & Frequency & Percent (\%) & Cumulative Percent \\
\hline \multirow[t]{2}{*}{ Valid } & strongly encourage & 76 & 60.3 & 60.3 \\
\hline & encourage & 22 & 17.5 & 77.8 \\
\hline
\end{tabular}




\begin{tabular}{|l|l|l|l|l|}
\hline & discourage & 17 & 13.5 & 91.3 \\
\hline & Strongly discourage & 11 & 8.7 & 100.0 \\
\cline { 2 - 5 } & Total & 126 & 100.0 & \\
\hline Missing & 0 & 29 & & \\
\hline Total & 155 & & \\
\hline
\end{tabular}

Table 7: Tradition as factor influencing remote development of CMSC in Nigeria

\begin{tabular}{|c|c|c|c|c|}
\hline & & Frequency & Percent & Cumulative Percent \\
\hline \multirow[t]{5}{*}{ VALID } & strongly encourage & 68 & 54.0 & 54.0 \\
\hline & encourage & 29 & 23.0 & 77.0 \\
\hline & discourage & 18 & $14 \cdot 3$ & 91.3 \\
\hline & strongly discourage & 11 & 8.7 & 100.0 \\
\hline & Total & 126 & 100.0 & \\
\hline MISSING & & 29 & & \\
\hline TOTAL & & 155 & & \\
\hline
\end{tabular}

Table 8: Organisational structure as an influencing factor in remote development of CMSC in Nigeria

obtaining certified qualification as a CSF remote development of CMSC in Nigeria

\begin{tabular}{|l|l|l|l|l|}
\hline \multirow{4}{*}{ VALID } & Strongly Encourage & 104 & 71.2 & 71.2 \\
\cline { 2 - 5 } & Encourage & 24 & 16.4 & 87.7 \\
\cline { 2 - 5 } & Strongly discourage & 2 & 1.4 & 89.0 \\
\hline & Discourage & 16 & 11.0 & 100.0 \\
\cline { 2 - 5 } & Total & 146 & 100.0 & \\
\hline MISSING & 9 & & \\
\hline TOTAL & 155 & & Percentage (\%) & Cumulative Percentage \\
\hline
\end{tabular}

Table 9: Certified qualification as a CSF in remote development of CMSC in Nigeria 


\begin{tabular}{|l|l|l|l|l|}
\hline \multicolumn{5}{|c|}{ obtaining respect of peers as a CSF remote development of CMSC in Nigeria } \\
\hline \multirow{4}{*}{ VALID } & Strongly Encourage & 63 & 43.2 & 43.2 \\
\cline { 2 - 5 } & Encourage & 43 & 29.5 & 72.6 \\
\cline { 2 - 5 } & Strongly Discourage & 2 & 1.4 & 74.0 \\
\cline { 2 - 5 } & Discourage & 38 & 26.0 & 100.0 \\
\cline { 2 - 5 } & Total & 146 & 100.0 & \\
\hline MISSING & & 9 & & \\
\hline TOTAL & 155 & & Percentage (\%) & Cumulative Percentage \\
\hline
\end{tabular}

Table 10: Respect of peers as a CSF in remote development of CMSC in Nigeria

\begin{tabular}{|l|l|l|l|l|}
\hline \multicolumn{5}{|c|}{ Promotion and career as a CSF remote development of CMSC in Nigeria } \\
\hline \multirow{3}{*}{ VALID } & Strongly Encourage & Frequency & Percentage (\%) & Cumulative Percentage \% \\
\cline { 2 - 5 } & Encourage & 12 & 89.7 & 89.7 \\
\hline & Discourage & 1 & 9.5 & 99.2 \\
\cline { 2 - 5 } & Total & 126 & .8 & 100.0 \\
\hline MISSING & 29 & 100.0 & \\
\hline TOTAL & 155 & & \\
\hline
\end{tabular}

Table 11: Promotion and career development as CSF in remote development of CMSC in Nigeria

\section{Willingness to learn as a CSF in remote development of CMSC in Nigeria}

\begin{tabular}{|l|l|l|l|l|}
\hline \multirow{3}{*}{ VALID } & Frequency & Percentage (\%) & Cumulative Percentage \% \\
\cline { 2 - 5 } & Strongly Encourage & 108 & 89.3 & 89.3 \\
\cline { 2 - 5 } & Encourage & 12 & 9.9 & 99.2 \\
\cline { 2 - 5 } & Discourage & 1 & .8 & 100.0 \\
\hline
\end{tabular}


AAM: Journal of Engineering, Design and Technology

\begin{tabular}{|l|l|l|l|l|}
\hline & Total & 121 & 100.0 \\
\hline MISSING & 0 & 34 & \\
\hline TOTAL & 155 & \\
\hline
\end{tabular}

Table 12: Willingness to learn as a CSF in remote development of CMSC in Nigeria 